were consistently greater than those obtained by Vincent et al (1969), but the slopes of the lines fitting the two sets of data were quite similar. Considering the differences in stimulus objects used, these results tend to corroborate those of the previous study. The question of the relative importance of various cues in distance discrimination is not answered by these data. The data indicate that, in the absence of terrain information, Ss are capable of making reasonably precise distance discriminations. Retinal image size probably makes the most significant contribution to this accuracy.

In view of the greater $\Delta \mathrm{D}$ values obtained in this study and the relatively large degree of between-S variability, additional data were collected using the same method and procedure described above for one of the Ss whose responses were most consistent. One hundred judgments were made for each of seven comparison-standard pairs. The standard distance used was $400 \mathrm{ft}$. The proximal and distal values of $\triangle D / D$ were $2.0 \%$ and $2.25 \%$, respectively, which are somewhat smaller than those reported above. These data indicate that $O$ sensitivity and experience are critical in determining $\Delta \mathrm{D}$ values, particularly for the tasks described earlier, but over a range of standard distances, the power function describing distance discrimination would not be significantly affected.

The results obtained from these reduced cue studies and the well documented usefulness of textural and context cues lends indirect support to Ross \& DiLollo's (1968) recent suggestion that $S s$ can and do shift the relative importance of particular stimulus attributes so as to maximize their ability to discriminate in the experimental situation.

\section{REFERENCES}

ARNOULT, M. D., VINCENT, R. J., BROWN, B. R., MARKLEY, R.P., \& HENSLEIGH, R.C.A description of the NASA-TCU space vision simulator. Technical Report, September 1968, Texas Christian University, Grant NGR 44009 018, National Aeronautics and Space Administration, CR 73305.

KUNNAPAS, $T$. Distance perception as a function of available visual cues. Journal of Experimental Psychology, 1968, 77, 523-529.

MARKLEY, R. P., BROWN, B. R., \& ARNOULT, M. D. Fractionation of distance in simulated space. Technical Report, January 1969, Texas Christian University, Grant NGR 44009018 . National Aeronautics and Space Administration, CR 73306.

ROSS, J., \& DiloLlo, V. A vector model for psychophysical judgment. Journal of Experimental Psychology, 1968, 77, (Monograph Supplement).

TEICHNER, W. H., KUBRICK, T. L., \& DISEK, E. $R$. Commonplace viewing and depth discrimination. Journal of the Optical Society of America, 1955, 45, 913-920.

VINCENT, R. J., BROWN, B. R.; MARKLEY, R. P., \& AR NOULT, M.D. Distance discrimination in a simulated space environment. Perception \& Psychophysics, 1969, 5, 235-238.

$$
\text { NOTE }
$$

1. This research and preparation of this paper was supported by Grant NGR 44009018 from the National Aeronautics and Space Administration to Texas Christian University; $M$ D. Arnoult was the principal investigator.

\title{
Persistence of GSR changes as a function of repeated verbal satiation of emotionally-charged words
}

\section{NICHOLAS S. DiCAPRIO and MARY-THOMAS TURNOCK, John Carroll University, Cleveland, Ohio 44118}

The effects of repeated verbal-satiation applications, i.e., rapid repetitions of words for several minutes at a time, was studied over the course of several weeks by means of GSR changes. Highly charged, personally relevant words were divided into experimental words and control words, equally matched on emotional-response intensity. The satiation treatment consisted of three 40-min periods occurring once a week, with the outcome that the formerly highly charged words that were satiated yielded significantly lower GSR tracings than did the highly charged but unsatiated words. The satiation effect persisted for at least a week, i.e., the time lapse between the last satiation session and the post-satiation test. GSR levels dropped more quickly after the first satiation, and continued to drop throughout the rest of the satiation sessions. Thus, the interpretation of the effects of reactive inhibition as the sole process involved in satiation was questioned.

One of the most characteristically human psychological functions involves the use of language symbols. Such language symbols acquire "meaning" through learning processes. The "real meaning" of a word, however, is ultimately a highly personal matter. Prolonged visual fixation of words, or long-continued repetitions of "emotionally charged" words, will produce change or loss of meaning of the words, i.e., a satiation effect. The loss or change of response may be thought of in two ways: the associative potential or cognitive aspect of the words, and the connotative aspect that includes the physiological reactions to the stimuli.

Severance \& Washburn (1907), using Ss' reports of loss of meaning of words that were visually fixated for several minutes, ascribed the satiation effects to oscillation of attention and a subsequent bre akdown of the stimulus words into "meaningless" units. The phenomenon of satiation was described by them as temporary. For the most part, this view has prevailed, even though later investigators have refined the concepts and methods of satiation considerably. For example, the loss of cognitive aspects of words has been measured by response latency (Baras, 1968), rareness of associations suggested by satiated words (Smith \& Raygor, 1956; Fillenbaum, 1963), and the number of associations that are suggested in a given period of time (Noble, 1952, Fillenbaum, 1963; Baras, 1968). The connotative aspect of words has been measured by use of the Osgood semantic-differential scales (Lambert \& Jakobovits, 1960). Mason (1941), using GSR changes in a preliminary study of satiation effects, demonstrated that GSR records can take the place of introspective reports as an indicator of satiation effects.

The purpose of the present study was to determine the extent to which emotional responses elicited by personally relevant verbal stimuli, and measured by GSR tracings as the indicator of satiation, could be reduced by the application of the satiation procedures. The hypothesis is that repeated application of satiation procedures will yield decreased and enduring GSR levels.

METHOD
Ten students taken from an upper-division psychology course, taught during a 5-week summer session, participated as $S s$ in the experiment. Each $S$ came once a week for 5 weeks according to the following schedule: a pre-satiation test session the 1st week, followed by three satiation sessions in the subsequent 3 weeks, and concluded with a final post-satiation test period the 5 th week. Ss were asked to list 20 personally relevant and 20 neutral words prior to testing procedures. To assist the Ss in identifying personally relevant words, both written and oral instructions were given with examples of such categories of sensitivity as names, places, dates, etc. The words were to be rated on a 5-point scale of intensity; this was done not only to aid the Ss, but also later to match the words with corresponding GSR levels. It should be noted that the words listed did not always produce GSR levels that matched the Ss' ratings of them (i.e., sometimes words 
produced no GSR response even though the $S$ had rated the word as highly personally significant, and vice versa). Taking this into consideration, the words that were finally selected for satiation and controls were those which consisted of correspondence of the Ss' ratings and objective GSR levels. GSR records were analyzed in terms of a 5-point scale of response intensity. In order for a word to be used in the experiment, there had to be agreement between GSR level and subjective rating (e.g., a subjective rating of 3 should agree with a GSR level of 3). After obtaining, in this manner, the critical and neutral words for each $S$, five pairs of emotionally charged words, matched for an equal level of response intensity, were identified for each $S$; one word of each pair was designated as a word to undergo satiation procedures, with the other acting as a control. The neutral words were used between critical words to eliminate residual emotional effects from the previous word.

The satiating sessions took place during the second, third, and fourth weeks. The procedure consisted of a warm-up period that lasted about $5 \mathrm{~min}$, during which the $S$ was attached to the operating GSR as he conversed with E. Following this, and while seated quietly with his eyes closed, the $S$ was given one of his critical words to repeat at a rate of two or three times a second for a 3 -min interval. This was followed by the presentation of a neutral word, and then, another critical one was presented as before. Thus, the $\mathrm{E}$ could note changes in response intensity as they occurred. After going through the five critical words in this manner, the satiation procedure was again applied, but with 1-min periods of satiation rather than 3-min ones. This later modification was introduced because the Ss reported fatigue. It should be noted that the length of each satiation session, allowing for warm-up period and presentation of critical and neutral words, was 35 to $40 \mathrm{~min}$ in duration.

The post-satiation test session, which occurred during the 5 th week, consisted of testing the responses to the five critical and five control words, with, of course, neutral words interspersed. To distinguish the control words from the neutral words, it should again be noted that the con trol words were matched in intensity with the experimental or satiated words. Thus, the satiated words could be compared with the nonsatiated or control words with respect to the galvanic skin response.

\section{RESULTS}

The results were based on 46 pairs of words, since the requirements of matching were quite strictly adhered to (a reduction from 200 pairs to 46 pairs). Since categories of response intensities, as measured by the
GSR, were employed as the response variable, a chi-square test was used to measure the changes from the pre-satiation test to the post-satiation test for both the experimental and control words. Only those responses of the 46 experimental and 46 control words that showed a decrease in GSR intensity were counted in order to test for satiation effects. Thirty-one of the experimental words decreased in response level from the pre-satiation to the post-satiation session, whereas, of the 46 control words, 16 yielded lower response levels on the post-satiation test as compared with their pre-satiation levels. The chi square for these changes in proportions $\left(\chi^{2}=9.78, \mathrm{df}=1\right.$ ) is significant at beyond the .005 level of significance.

A second analysis of the data was undertaken because of the likelihood of changes in response that would occur from warm-up effects to the test situation over the 5-week period, even though time was allotted for the $S$ to become adjusted to the GSR situation during each session. Another factor considered was the fluctuation of general response from session to session, i.e., the influence of a person's change in mood from week to week. Thus, to control for these factors and to more clearly highlight the satiating effect, only small or no responses, as measured by the GSR, were considered for experimental and control words on the final test. Of the 46 satiated words, 30 elicited little or no response in the final test, contrasted with 18 of the 46 control words. The chi square for this difference $\left(\chi^{2}=6.27, \mathrm{df}=1\right)$ is significant at beyond the .025 level of significance.

It may be concluded from these results that the hypothesis, within the limits of the experiment, was confirmed; satiation effects endured for at least a week (time lapse between last satiation session and post-satiation test). The E observed during the second and third satiation periods that the satiation effects occurred more rapidly during the course of verbal repetition, as reflected by the decrease in GSR tracings. This observation suggests that the satiation effects began with the first satiation application and persisted throughout the remaining periods.

\section{DISCUSSION}

The results indicate that a significant reduction in GSR levels did occur as a result of the satiation treatments. It can be inferred that the satiation effect endured for at least 1 week, the time between the fourth and fifth sessions. The evidence further suggests the likelihood that the satiation effects began earlier. Although the data were not specifically analyzed to deal with this aspect, as was earlier reported, the reduction in GSR levels occurred sooner during the second and third satiation sessions than during the first; this indicates that the first satiation session left some residual effects.

Several of the major investigators of this phenomenon (Smith \& Raygor, 1956; Lambert \& Jakobovits, 1960; Jakobovits \& Lambert, 1962) have assumed that the process is temporary, based on the view that rapid repetition of a word produces reactive inhibition, which renders the word ineffective as a stimulus. The reactive inhibition is soon reduced as a function of time, and the stimulus is again restored to its original pre-satiation level. The results of the present experiment suggest that repeated satiation procedures involve something other than the buildup of reactive inhibition $\left(\mathrm{I}_{\mathrm{r}}\right)$ in that the GSR records indicate some reduction in reaction to personally charged words that endured at least 1 week and probably more; this contrasts sharply with the usually rapid dissipation of $I_{r}$ effects that usually involves only minutes (Lambert \& Jakobovits, 1960).

Assuming these results are reliable, the implications for application of the satiation effects in certain forms of behavior pathology are suggested. Numerous psychological disturbances involve aberrations in ideational activity, as in the case of phobias, obsessions, aversiors, etc. It should be possible to use satiation procedures to reduce the intensity of "feeling" associated with such ideational contents. If, by repeated satiation applications, the intensity can be reduced, not only would there be an immediate alleviation of the emotional reaction, but the evidence of the present study indicates that the effects may be enduring. With occasional reapplications of the satiation procedures, whenever the unwanted responses would recur, the affective verbal stimuli could again be neutralized.

\section{REFERENCES}

BARAS, H. L. Effect of mode of presentation of semantic satiation. Psychonomic Science, 1968, 11, 345-346.

FILLENBAUM, S. Verbal satiation and changes in meaning of related items. Journal of Verbal Learning \& Verbal Behavior, 1963, 2, 263-271.

JAKOBOVITS, L. A., \& LAMBERT, W. E. Semantic satiation among bilinguals. Joumal of Experimental Psychology, 1962, 62, 576-582.

LAMBERT, W. E., \& JAKOBOVITS, L. A. Verbal satiation and changes in the intensity of meaning. Joumal of Experimental Psychology, $1960,60,376-383$.

MASON, M. Changes in the galvanic skin response accompanying reports of changes in meaning during oral repetition. Joumal of General Psychology, 1941, 25, 353-401.

NOBLE, C. E. An analysis of meaning. Psychological Review, 1952, 59, 421-430.

SEVERANCE, E., \& WASHBURN, M. F. The loss of associative power in words after long fixation. American Journal of Psychology, $1907,18,182-186$.

SMITH, D. E. P., \& RAYGOR, A. L. Verbal satiation and personality. Joumal of Abnormal \& Social Psychology, 1956, 52, 323-326. 